\title{
The HrpN Effector of Erwinia amylovora, Which Is Involved in Type III Translocation, Contributes Directly or Indirectly to Callose Elicitation on Apple Leaves
}

\author{
Tristan Boureau, ${ }^{1,2,3}$ Sabrina Siamer, ${ }^{1,2,3}$ Claude Perino, , ,2,3 Stéphane Gaubert,, ${ }^{1,2,3}$ Oriane Patrit, ${ }^{1,2,3}$ \\ Alexandre Degrave, ${ }^{1,2,3}$ Mathilde Fagard, ${ }^{1,2,3}$ Elisabeth Chevreau, ${ }^{4}$ and Marie-Anne Barny ${ }^{1,2,3}$ \\ ${ }^{1}$ INRA, UMR217, LIPP, 16 rue Claude Bernard, 75231 Paris cedex 05, France; ${ }^{2}$ UPMC, Université Paris VI, UMR217, LIPP, \\ 16 rue Claude Bernard, 75231 Paris cedex 05, France; ${ }^{3}$ AgroParisTech, UMR217, LIPP, 16 rue Claude Bernard, 75231 \\ Paris cedex 05, France; ${ }^{4}$ UMR GenHort (INRA/ACO/UA), IFR149, 42 rue Georges Morel, 49071 Beaucouzé Cedex, France
}

Submitted 17 September 2010. Accepted 7 January 2011.

\begin{abstract}
Erwinia amylovora is responsible for fire blight of apple and pear trees. Its pathogenicity depends on a type III secretion system (T3SS) mediating the translocation of effectors into the plant cell. The DspA/E effector suppresses callose deposition on apple leaves. We found that $E$. amylovora and Pseudomonas syringae DC3000 tts mutants or peptide flg22 do not trigger callose deposition as strongly as the $d \operatorname{sp} \mathrm{A} / \mathrm{E}$ mutant on apple leaves. This suggests that, on apple leaves, callose deposition is poorly elicited by pathogenassociated molecular patterns (PAMPs) such as flg22 or other PAMPs harbored by tts mutants and is mainly elicited by injected effectors or by the T3SS itself. Callose elicitation partly depends on HrpW because an $h r p W-d s p \mathrm{~A} / \mathrm{E}$ mutant elicits lower callose deposition than a $d s p \mathrm{~A} / \mathrm{E}$ mutant. Furthermore, an $h r p \mathrm{~N}-d s p \mathrm{~A} / \mathrm{E}$ mutant does not trigger callose deposition, indicating that $\mathrm{HrpN}$ is required to trigger this plant defense reaction. We showed that HrpN plays a general role in the translocation process. Thus, the HrpN requirement for callose deposition may be explained by its role in translocation: HrpN could be involved in the translocation of other effectors inducing callose deposition. Furthermore, HrpN may also directly contribute to the elicitation process because we showed that purified HrpN induces callose deposition.
\end{abstract}

During pathogen attack, plant basal defense responses can be triggered by recognition of conserved pathogen-associated molecular patterns (PAMPs). Typical PAMPs are microbial molecules that are critical for the pathogen and, therefore, difficult to modify without loss of functionality. For example, plants can recognize components of gram-negative bacteria such as lipopolysaccharide, flagellin, peptidoglycan, and elongation factor TU. The response induced by this recognition is known as PAMP-triggered immunity (PTI) (Jones and Dangl 2006). A well-characterized example of PTI in plants is the

T. Boureau and S. Siamer contributed equally to this work.

Current address for T. Boureau: UMR PaVé, 42 rue Georges Morel, 49071 Beaucouzé, France

Corresponding author: M.-A. Barny; Telephone: +33 1440817 02; Fax: +3314408 1631; E-mail: barny@ agroparistech.fr

* The $\boldsymbol{e}$-Xtra logo stands for "electronic extra" and indicates that three supplementary figures are published online and that Figures 1 and 5 appear in color online. recognition and subsequent immune response to the conserved flg22 peptide of bacterial flagellin by the FLS2 receptor kinase of Arabidopsis thaliana (Felix et al. 1999; Zipfel et al. 2004). Several gram-negative bacteria defeat PTI by injecting into host cells, via the type III secretion system (T3SS), type three effectors (T3E) that suppress PTI. The activities of T3E in the host cell can then be recognized by resistance proteins in a second level of defense known as effector-triggered immunity (ETI). ETI and PTI induce similar defense responses, including ion fluxes, reactive oxygen species (ROS), and callose ( $\beta$ 1,3-glucan) deposition in the cell wall (Boller and Felix 2009; Tsuda et al. 2008) but ETI usually results in a localized, rapid programmed cell death known as the hypersensitive response (HR) (Heath 2000). To successfully invade their host plant, pathogenic bacteria must defeat both PTI and ETI, and it has become increasingly apparent that many T3E suppress PTI or ETI (Block et al. 2008; Cui et al. 2009; Guo et al. 2009).

Fire blight, caused by the gram-negative bacterium Erwinia amylovora, is a devastating disease of rosaceous plants that has a global economic importance for apple and pear production. E. amylovora pathogenicity involves both the biosynthesis of a capsular polysaccharide named amylovoran and a functional T3SS (Barny et al. 1990; Bugert and Geider 1995). To date, 12 effectors transiting through the T3SS have been identified (Nissinen et al. 2007).

Among these effectors, HrpN and HrpW effectors belong to the harpin family. Harpins are a subset of T3E found in many phytopathogenic bacteria. Harpins are able to induce an HR on nonhost tobacco plants (Gaudriault et al. 1998; Kim and Beer 1998; Wei et al. 1992), and plant defense reactions elicited by purified HrpN on nonhost plants have been extensively studied. HrpN has been shown to trigger an oxidative burst (Baker et al. 1993; Cessna and Low 2001), mitogen-activated protein kinase kinase activation (Adam et al. 1997), cytosolic $\left[\mathrm{Ca}^{2+}\right]$ elevation, (Cessna et al. 2001; He et al. 1994; Pike et al. 1998), defense gene activation (Dong et al. 1999; Peng et al. 2003), and ion fluxes modulation (El Maarouf et al. 2001; Pike et al. 1998; Popham et al. 1995).

Effects of HrpN on host plants remain more elusive. HrpN does not trigger cell death in the leaves of apple plants (Malnoy et al. 2005). HrpN sprayed on an apple tree induces resistance to blue mold and scab diseases (de Capdeville et al. 2003; Percival et al. 2009), indicating that HrpN triggers systemic acquired resistance (SAR) on host plants. Compared with the wild-type strain, an $h r p \mathrm{~N}$ mutant provokes a reduced oxidative burst, suggesting that HrpN contributes to the generation of 
oxidative stress in apple plants (Venisse et al. 2003). However, purified $\mathrm{HrpN}$ fails to induce $\mathrm{H}_{2} \mathrm{O}_{2}$ production on apple cells (Reboutier et al. 2007a). Furthermore, purified HrpN does not elicit cell death on apple cells and triggers opposite ion fluxes responses on the nonhost $A$. thaliana cells and on the host apple cells, highlighting the fact that HrpN is perceived differently by different plants (Reboutier et al. 2007a).

$\mathrm{HrpN}$ has been shown to enhance the efficiency of DspA/E translocation into the plant cells (Bocsanczy et al. 2008). However, it remains unclear whether this effect is specific to the translocation of DspA/E or is general to the translocation process. Surprisingly, HrpN and HrpW play opposite roles during the interaction: $h r p \mathrm{~N}$ mutants have severely impaired pathogenesis on host plants and elicit weak HR on nonhost plants, whereas $h r p \mathrm{~W}$ mutants are slightly more pathogenic than the wild-type strain and elicit HR more strongly (Barny 1995; Gaudriault et al. 1998). Purified HrpN and HrpW also have antagonistic effects on ion fluxes in A. thaliana cell suspension culture (Reboutier et al. 2007b), showing that these harpins have different roles during the interaction.

The DspA/E effector is essential to the fire blight disease process because $d s p \mathrm{~A} / \mathrm{E}$ mutants are nonpathogenic and unable to grow on host plants (Barny et al. 1990; Bogdanove et al. 1998; Gaudriault et al. 1997). DspA/E acts as a major cell death inducer (Boureau et al. 2006; Oh et al. 2007) and has been involved in the generation of an oxidative stress in planta on host plants (Venisse et al. 2003). Furthermore, it has been shown that DspA/E suppresses callose deposition on host plants (DebRoy et al. 2004). Whether callose deposition suppressed by DspA/E on apple plants is PTI or ETI triggered is currently unknown. On host apple plants, the generation of an oxidative burst, lipid peroxidation, and the production and accumulation of several pathogenesis-related proteins are dependent on the presence of a functional T3SS (Venisse et al. 2001, 2002, 2003), suggesting that the E. amylovora T3E, or the T3SS itself, are genuine inducers of these plant-defense reactions on apple plants.

Along the same lines, we showed here that E. amylovora and Pseudomonas syringae tts mutants or the flg22 peptide are poor at inducing callose deposition on apple leaves compared with a $d s p \mathrm{~A} / \mathrm{E}$ mutant. Therefore, callose deposition induced by the E. amylovora $d s p \mathrm{~A} / \mathrm{E}$ mutant on apple leaves mainly depends on T3E or on the T3SS and is related to ETI. We then investigated whether HrpN and HrpW harpins are involved in callose deposition. We found that $\mathrm{HrpN}$ is required for and HrpW contributes to callose accumulation in a $d s p \mathrm{~A} / \mathrm{E}$ mutant background. The requirement for $\mathrm{HrpN}$ in callose elicitation led us to investigate its role in translocation. We showed that $\mathrm{HrpN}$ plays a general role in the translocation process, therefore raising the possibility that it promotes the translocation of several T3E which contribute to callose elicitation. In addition, HrpN may also be involved directly in the elicitation process because we showed that purified HrpN induces callose deposition.

\section{RESULTS}

\section{Callose deposition on apple leaves is poorly induced} by $\boldsymbol{E}$. amylovora and $\boldsymbol{P}$. syringae tss mutants or flg22 peptide.

As already observed by DebRoy and associates (2004), callose deposition is induced on apple leaves infiltrated with a $d s p \mathrm{~A} / \mathrm{E}$ mutant whereas it is not induced by the wild-type $E$. amylovora strain $16 \mathrm{~h}$ postinoculation (hpi) (Fig. 1A). Surprisingly, the inoculation of apple leaves with two different $E$. amylovora tts mutants affected in hrcV (PMV6023) or hrc C (PMV6119), respectively, did not induce callose deposition as strongly as the $d s p \mathrm{~A} / \mathrm{E}$ mutant (Fig. 1A and B). We next exam- ined whether callose deposition was triggered by a $P$. syringae tts mutant or by the peptide flg22 that are both well-known elicitors of callose deposition in Arabidopsis thaliana (Felix et al. 1999; Hauck et al. 2003; Zipfel et al. 2004). Again, we found that $\mathrm{flg} 22$ and the $P$. syringae tts mutant did not induce callose deposition as strongly as the $d s p \mathrm{~A} / \mathrm{E}$ mutant (Fig. 1C). The E. amylovora hrc C mutant, $P$. syringae tts mutant, and flg22 peptide induced slightly more callose deposits than the water control and, although these inductions were not statistically different from the one observed with the water control, it nevertheless suggested that these treatments elicited a weak

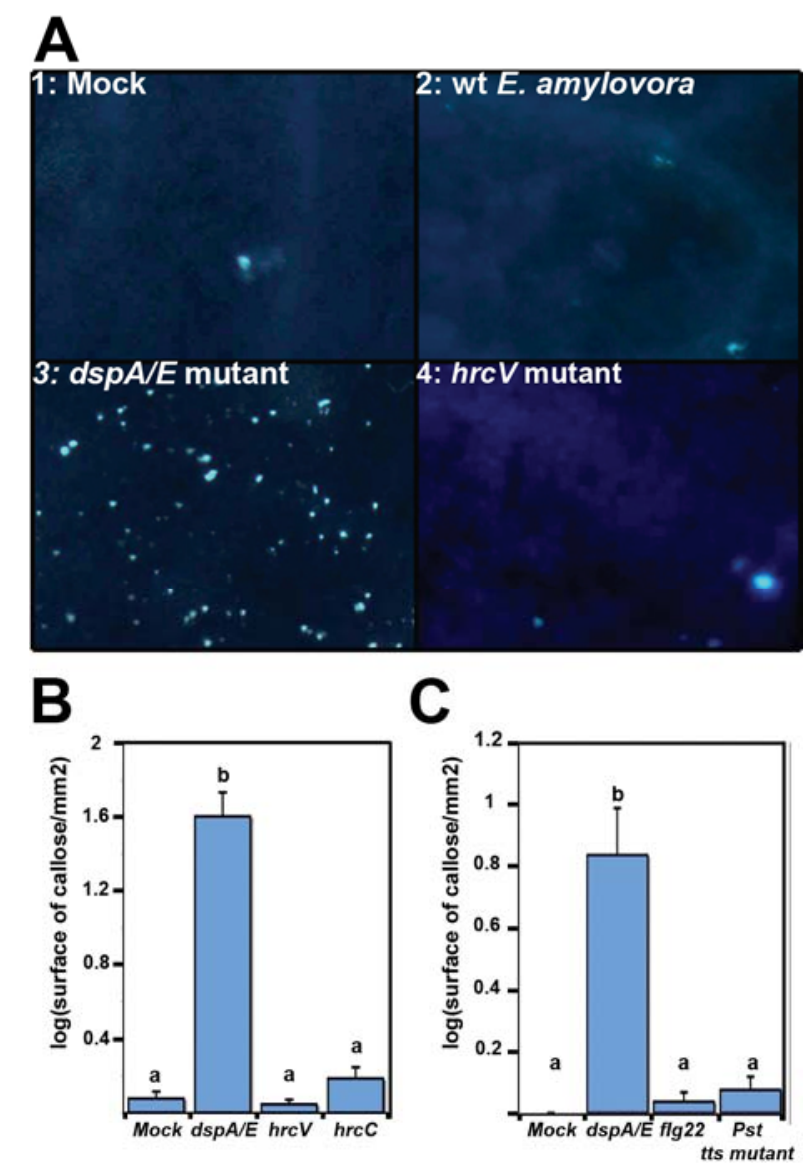

Fig. 1. Quantification of callose deposition in response to flg22 peptide and tts mutants of Erwinia amylovora or Pseudomonas syringae. A, Epifluorescence micrograph of apple leaf disks infiltrated with various $E$. amylovora strains. After staining with aniline blue, callose deposits appear as fluorescent dots.1: mock, 2: E. amylovora wild-type (wt) strain, 3: E. amylovora dspA/E mutant, 4: E. amylovora tts mutant PMV6023 (hrcV). $\mathbf{B}$ and $\mathbf{C}$, Total area of callose deposition was determined with Image $\mathbf{J}$ software. Data were normalized by $\log$ transformation for statistical analysis. B, Quantification of callose deposit following inoculation with mock, the E. amylovora dspA/E mutant, and two different E. amylovora tts mutants: PMV6023 ( $h r c \mathrm{~V}$ ) and PMV6119 (hrcC). Histograms show means of total area of callose deposition observed for 50 images from five different leaf disks. Callose deposition observed following inoculation with the $d s p \mathrm{~A} / \mathrm{E}$ mutant is significantly different than those observed following mock, $h r c \mathrm{~V}$ mutant PMV6023, or $h r c \mathrm{C}$ mutant PMV6119 inoculations. Bars represent standard errors. Columns with different letters are statistically different according to Student's $t$ tests $(P$ value $<0.05)$. C, Quantification of callose deposit following inoculation with mock, E. amylovora $d s p A / \mathrm{E}$ mutant, peptide $\mathrm{flg} 22$, and $P$. syringae tss mutant. Histograms show means of total area of callose deposition observed for 50 images from five different leaf disks. Callose deposition observed following inoculation with the $\mathrm{dspA} / \mathrm{E}$ mutant is significantly different than those observed following mock, $P$. syringae tss mutant, or flg22 peptide inoculations. Bars represent standard errors. Columns with different letters are statistically different according to Student's $t$ tests $(P$ value $<0.05)$ 
callose response. However, the strong callose deposition observed following infiltration of apple leaves with the $d s p \mathrm{~A} / \mathrm{E}$ mutant indicates that callose deposition is mainly induced either by the T3SS itself or by T3E.

\section{Induction of callose deposition}

by the plant pathogen $E$. amylovora requires

HrpN and the participation of HrpW.

Several T3E have been identified in E. amylovora. Among them, the harpins HrpN and HrpW are good candidate callose

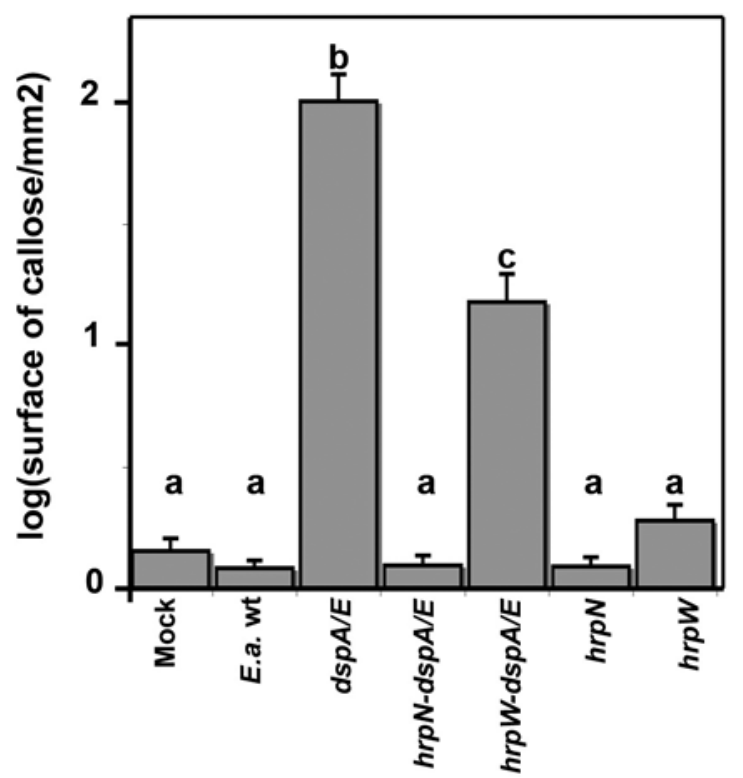

Fig. 2. Quantification of callose deposition in apple leaves following inoculation with various Erwinia amylovora mutants. Total area of callose deposition was determined with Image J software. Data were normalized by log transformation for statistical analysis. Histograms show means of the values obtained for the 50 images displaying the strongest callose deposition from five leaf disks from one experiment and the data presented are representative of the results obtained in three independent experiments. The $d s p \mathrm{~A} / \mathrm{E}$ mutant and the $h r p \mathrm{~W}-d s p \mathrm{~A} / \mathrm{E}$ double mutant induce callose deposition significantly more strongly than the mock, wild-type (wt) E. amylovora, $h r p \mathrm{~N}$ mutant, $h r p \mathrm{~W}$ mutant, and $h r p \mathrm{~N}-d s p \mathrm{~A} / \mathrm{E}$ double mutant. Bars represent standard errors. Columns with different letters are statistically different according to Student's $t$ tests $(P$ value $<0.05)$. inducers because these proteins induce HR on nonhost tobacco leaves (Kim and Beer 1998; Wei et al. 1992). We assessed whether HrpN or HrpW are involved in callose deposition in apple leaves by evaluating callose deposition following the infiltration with $h r p \mathrm{~N}-d s p \mathrm{~A} / \mathrm{E}$ and $h r p \mathrm{~W}-d s p \mathrm{~A} / \mathrm{E}$ double mutants. As controls, we also tested the single $h r p \mathrm{~N}$ and $h r p \mathrm{~W}$ mutants and found that they did not elicit callose deposition (Fig. 2). The $h r p \mathrm{~W}-d s p \mathrm{~A} / \mathrm{E}$ mutant induced callose deposition but less than the $d s p \mathrm{~A} / \mathrm{E}$ mutant, indicating that HrpW participates in the observed induction of callose deposition. The infiltration of apple leaves with the $h r p \mathrm{~N}-d s p \mathrm{~A} / \mathrm{E}$ mutant did not result in callose deposition (Fig. 2). When apple leaves were infiltrated with the $h r p \mathrm{~N}-d s p \mathrm{~A} / \mathrm{E}$ mutant complemented with either low- or high-copy plasmids carrying the $h r p \mathrm{~N}$ gene, the observed callose deposition was as strong as the one observed following inoculation with the $d s p \mathrm{~A} / \mathrm{E}$ mutant (Supplementary Fig. S2). Altogether, these results indicate that the HrpN protein is required for the induction of callose deposition.

\section{HrpN is injected during the interaction and participates in the translocation process.}

HrpN has been implicated in translocation of the T3E DspA/E into the plant cells and has been shown to be weakly translocated into the plant cells (Bocsanczy et al. 2008). The strict requirement for $\mathrm{HrpN}$ in callose deposition suggests that HrpN could play a more general role in the translocation process than previously shown. To test this hypothesis, we constructed C-terminal translational CyaA fusions, in which the cyaA gene was fused to a sequence encoding the $200 \mathrm{~N}$-terminal amino acids of HrpN or HrpW, and assessed the translocation of the fusion proteins generated. The CyaA protein converts ATP to cAMP only in the presence of eukaryotic calmodulin and is widely used as a reporter system for effector translocation: the accumulation of cAMP reflects translocation of the fusion protein (Sory and Cornelis 1994). The $h r p \mathrm{~N}_{1-200}:: c y a \mathrm{~A}$ fusion and the $h r p \mathrm{~W}_{1-200}:: c y a \mathrm{~A}$ fusion, encoded by $\mathrm{pSG} 46$ and pSG44, respectively, were introduced into the wild-type $E$. amylovora strain, the $h r c \mathrm{~V}$ tts mutant, and the $h r p \mathrm{~N}$ mutant. The transformed strains were then used to infiltrate apple leaves, in which we measured cAMP accumulation. We could detect a significant amount of cAMP in apple leaves infiltrated with the wild-type E. amylovora strain carrying plasmids encoding the $h r p \mathrm{~N}_{1-200^{-}}-c y a \mathrm{~A}$ or $h r p \mathrm{~W}_{1-200^{-}}-c y a \mathrm{~A}$ fusions but not in leaves infiltrated with the $t t s$ mutant carrying one of these plas-

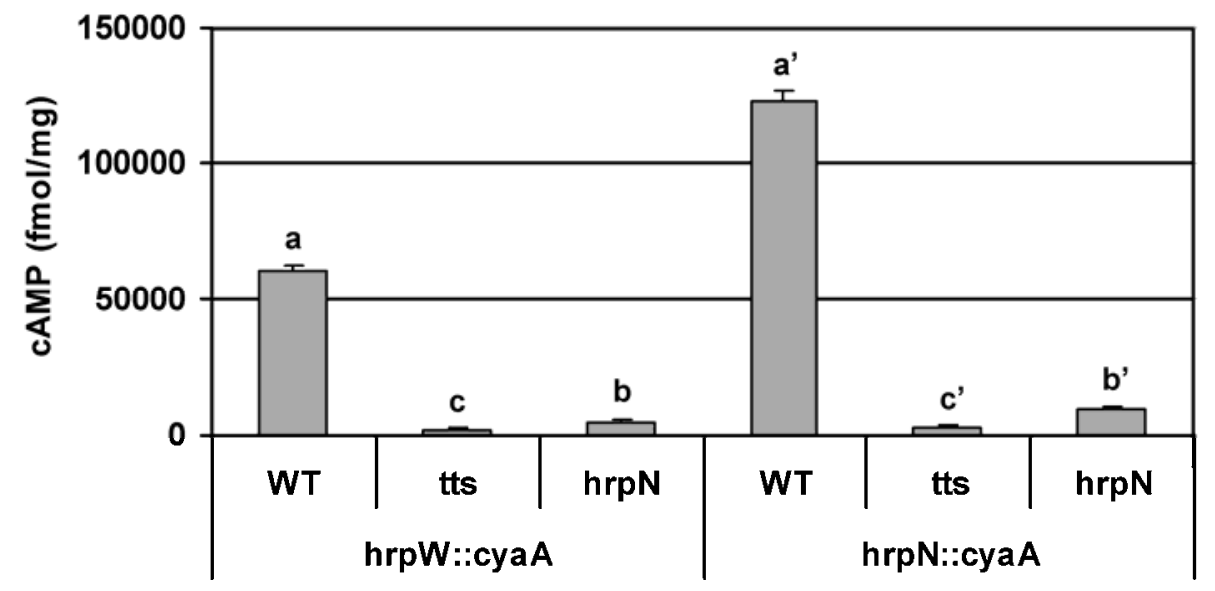

Fig. 3. Translocation of $\mathrm{HrpW}_{1-200}-\mathrm{CyaA}$ and $\mathrm{HrpN}_{1-200}-\mathrm{CyaA}$ into plant cells by Erwinia amylovora wild-type (WT) and mutant strains. WT strain

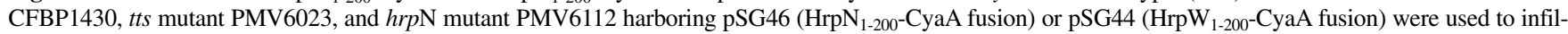
trate apple leaves. Leaf samples were taken $24 \mathrm{~h}$ after infiltration and the amount of cAMP was determined. Values shown are the means and standard errors for at least 10 measurements. Experiments were repeated two times, with similar results. Student $t$ test comparisons were performed between the WT strain CFBP1430, the tts mutant PMV6023, and the hrpN mutant PMV6112 harboring pSG44 (a, b, and c) or pSG46 (a', b', and c'). Columns with different letters are statistically different according to Student's $t$ tests $(P$ value $<0.05)$. 
mids (Fig. 3). Thus, both $\mathrm{HrpN}_{1-200}-\mathrm{CyaA}$ and $\mathrm{HrpW}_{1-200}-\mathrm{CyaA}$ were translocated into the host plant by the E. amylovora T3SS. Translocation of the $\mathrm{HrpN}_{1-200}-\mathrm{CyaA}$ was slightly more efficient than translocation of $\mathrm{HrpW}_{1-200}-\mathrm{CyaA}$ (Fig. 3). When apple leaves were infiltrated with the $h r p \mathrm{~N}$ mutant strain carrying plasmids encoding the $h r p \mathrm{~N}_{1-200^{-}}$cya $\mathrm{A}$ or the $h r p \mathrm{~W}_{1-200^{-}}$ cyaA fusions, the amount of cAMP detected was lower than that observed with the wild-type E. amylovora strain (Fig. 3), indicating an important role for $\mathrm{HrpN}$ in the translocation of both fusion proteins. Nevertheless, the amount of cAMP detected when the fusions were carried by the $h r p \mathrm{~N}$ mutant was slightly higher than the amount of cAMP detected when the fusions were carried by the tts mutant (Fig. 3), indicating that injection was strongly impaired but not abolished in an $h r p \mathrm{~N}$ mutant background.

\section{Purified HrpN elicits callose deposition but} not $\mathrm{O}_{2}{ }^{--}$production when infiltrated into apple leaves.

Because we have shown that HrpN and HrpW are involved in the induction of callose deposition, we wondered whether these T3E could be direct inducers of callose deposition. Therefore, we infiltrated apple leaves with purified HrpN or HrpW proteins. HrpW was unable to induce callose deposition on apple leaves but HrpN induced significant levels of callose deposition on apple leaves (Fig. 4). This suggests that $\mathrm{HrpN}$ may be a direct inducer of callose deposition.

Because the $h r p \mathrm{~N}$ mutant had been previously shown to be impaired in ROS elicitation (Venisse et al. 2003), we also checked whether purified HrpN could trigger $\mathrm{O}_{2}{ }^{--}$elevation when infiltrated into apple leaf disks. Apple leaf disks were infiltrated with the wild-type E. amylovora strain, purified $\mathrm{HrpN}$, or the water control and, at $16 \mathrm{hpi}$, disks were infiltrated with nitroblue tetrazolium (NBT). Accumulation of an insolu-

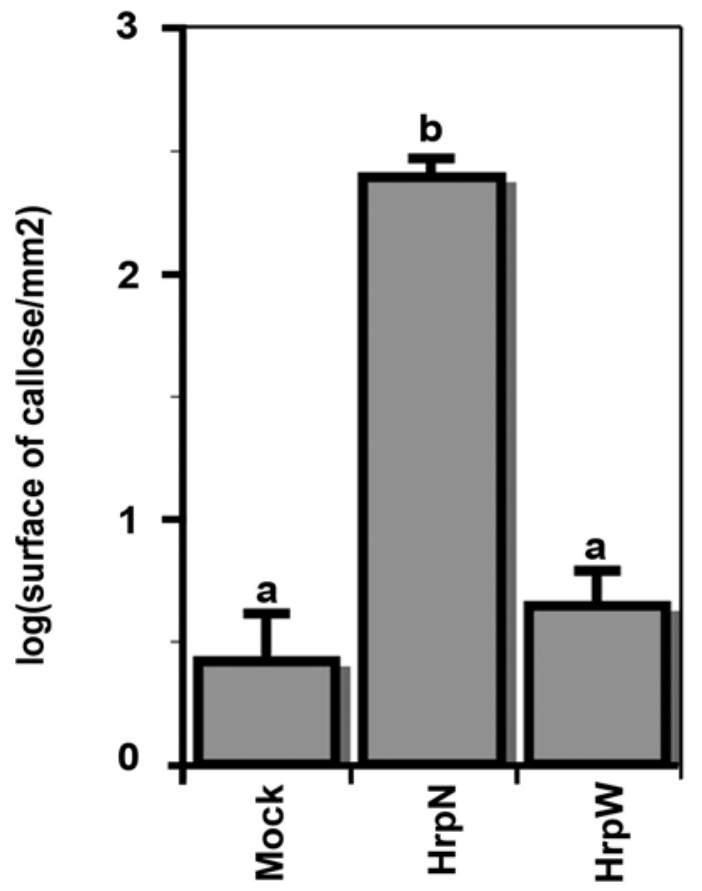

Fig. 4. Quantification of callose deposition in apple leaves following inoculation with purified harpin proteins. Total area of callose deposition was determined with Image J software. Data were normalized by $\log$ transformation for statistical analysis. Histograms show means of the values obtained for 25 images from four different leaf disks. Callose deposition observed following inoculation with purified $\mathrm{HrpN}$ protein is significantly different than that observed following inoculations with water (mock) or purified HrpW. Bars represent standard errors. Columns with different letters are statistically different according to Student's $t$ tests $(P$ value $<0.05)$. ble blue-colored formazan (reduced NBT) is an indicator of the generation of ROS, in particular $\mathrm{O}_{2}^{-{ }^{-}}$(Doke 1983). Following infiltration with the wild-type E. amylovora strain, a blue staining was observed indicating that, as already described by Venisse and associates (2002), the wild-type E. amylovora strain induces ROS formation on apple plants. In contrast, leaf disks infiltrated with purified HrpN or the water control were poorly stained (Fig. 5), suggesting that purified $\mathrm{HrpN}$ is not a strong inducer of $\mathrm{O}_{2}^{--}$production on apple.

\section{DISCUSSION}

The E. amylovora DspA/E effector efficiently suppresses callose deposition on apple leaves (DebRoy et al. 2004). We showed here that E. amylovora and P. syringae tts mutants or peptide flg22 are weak inducers of callose deposition in apple leaves. Whether this is specific to the apple cultivar used in this study or true for other apple cultivars remains to be determined. These results further indicate that the callose deposition observed with the $d s p \mathrm{~A} / \mathrm{E}$ mutant is induced either by the T3SS itself or by T3E and, therefore, is ETI related. DspA/E belongs to the AvrE effector family (Bogdanove et al. 1998; Kvitko et al. 2009) and AvrE has been previously found to suppress PTI-dependent callose induced by a $P$. syringae tts mutant (DebRoy et al. 2004). Therefore, it appears that members of the AvrE family of effectors suppress both PTI-induced and ETI-induced callose deposition.

The fact that callose is mainly induced by ETI on apple leaves gives us the opportunity to study which T3E are involved in callose elicitation. We showed that HrpW contributes to callose induction but does not play a major role because the $h r p \mathrm{~W}-d s p \mathrm{~A} / \mathrm{E}$ double mutant induced weaker callose deposition than the single $d s p \mathrm{~A} / \mathrm{E}$ mutant but was still able to elicit

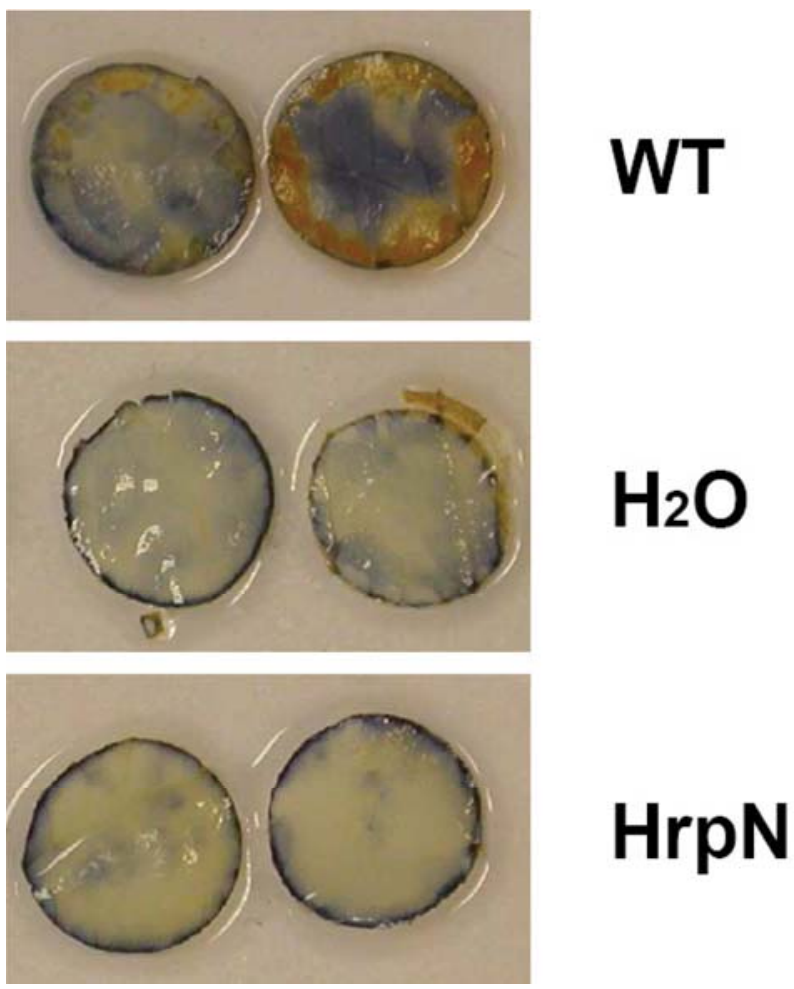

Fig. 5. Nitroblue tetrazolium staining of apple leaves was performed $16 \mathrm{~h}$ following infiltration with the wild-type Erwinia amylovora strain (WT), water $\left(\mathrm{H}_{2} \mathrm{O}\right)$, or purified $\mathrm{HrpN}$ protein $(10 \mu \mathrm{M})$. Blue staining indicates the presence of $\mathrm{O}_{2}^{--}$(Doke 1983). Blue staining is observed following inoculation with the WT E. amylovora strain. Faint staining is observed following inoculation with water or purified HrpN. 
this reaction. In contrast, the $\mathrm{HrpN}$ protein is required to induce callose deposition because the $h r p \mathrm{~N}-d s p \mathrm{~A} / \mathrm{E}$ mutant did not induce callose deposition. These results indicate that both harpins are involved, at different levels, in callose elicitation on apple leaves. It also highlights the importance of DspA/E in suppressing callose deposition that would otherwise be elicited in an HrpN- and HrpW-dependent manner.

HrpN had been shown to be involved in the translocation of DspA/E into plant cells (Bocsanczy et al. 2008). However, it remained unclear whether the role of $\mathrm{HrpN}$ in translocation was restricted to $\mathrm{DspA} / \mathrm{E}$. The strict HrpN requirement for callose elicitation led us to investigate whether it plays a more general role in the translocation process. We showed here that HrpN does not only facilitate the translocation of DspA/E but also plays a general role in the translocation process because it also facilitates its own translocation and HrpW translocation. However, other as yet unidentified proteins are also likely to contribute to the translocation process in E. amylovora. Indeed, we observed low levels of translocation of $\mathrm{HrpN}_{1-200}:$ CyaA and $\mathrm{HrpW}_{1-200}:: \mathrm{CyaA}$ in the $h r p \mathrm{~N}$ mutant background but these levels were nonetheless higher than those observed in the $t$ ts mutant background. A similar observation was made by Bocsanczy and associates (2008) with a DspA/ $\mathrm{E}_{1-773}:$ CyaA fusion protein. Furthermore, an $h r p \mathrm{~N}$ mutant is weakly aggressive but still is able to produce symptoms on apple plants, conversely to a $d s p \mathrm{~A} / \mathrm{E}$ mutant, which is totally nonpathogenic (Barny 1995). This phenotype suggests that the DspA/E protein is weakly injected in an $h r p \mathrm{~N}$ background. Altogether, this indicates that $\mathrm{HrpN}$, although playing an important role in the translocation process, is not strictly required for translocation. This suggests that other, as-yet-unknown proteins are involved in the translocation process, playing a minor role, additive or redundant with HrpN. A similar situation has already been described with $P$. syringae, where a consortium of partly redundant translocators, including four proteins of the harpin family (HrpZ1, HrpW1, HopP1, and HopAK1) and HrpK1, cooperate to form the T3SS translocon (Kvitko et al. 2007).

We investigated the possibility of $\mathrm{HrpN}$ playing a direct role in the elicitation of callose deposition. Significant callose deposition was observed following infiltration with the purified $\mathrm{HrpN}$ protein, consistent with its direct recognition by the plant. However, callose deposition was only induced with a high concentration of $\mathrm{HrpN}(10 \mu \mathrm{M})$. Nevertheless, it is interesting to note that purified HrpW at the same concentration did not induce callose deposition, indicating that the reaction observed with purified HrpN is unlikely to be an artifact solely due to the protein concentration. We also observed that transgenic apple plants constitutively producing HrpN accumulate callose spontaneously in the absence of pathogen challenge (Supplementary Fig. S3). Although this result has to be confirmed by studying other transgenic lines, it also suggests that HrpN may be a direct inducer of callose deposition. The induction of salicylic acid-dependent plant defense responses, such as callose deposition, by purified HrpN was expected because purified $\mathrm{HrpN}$ has been previously reported to induce SAR and protect apple plants against scab and blue mold diseases (de Capdeville et al. 2003; Percival et al. 2009). However, HrpN is not the unique T3SS-associated callose elicitor. Indeed, we also showed that HrpW contributes to callose elicitation. Due to the general role of $\mathrm{HrpN}$ in the translocation process, it is also possible that HrpN promotes the translocation of one or several unidentified T3E which also contribute to callose elicitation.

Because an $h r p \mathrm{~N}$ mutant is impaired in ROS elicitation (Venisse et al. 2003), we also investigated whether $\mathrm{O}_{2}{ }^{--}$production was elicited by purified HrpN. We did not detect a specific induction of $\mathrm{O}_{2}{ }^{--}$production by purified HrpN. This result is in agreement with previous results showing that purified HrpN does not induce $\mathrm{H}_{2} \mathrm{O}_{2}$ production on apple suspension cells (Reboutier et al. 2007a). Therefore, it is likely that the involvement of HrpN in ROS elicitation is indirect. Because $\mathrm{HrpN}$ is involved in translocation, the impaired ROS elicitation observed with the $h r p \mathrm{~N}$ mutant probably reflects the fact that HrpN promotes the translocation of one or several T3E that are involved in ROS elicitation.

One could wonder whether HrpN is eliciting callose deposition as part of the T3SS tip complex. Indeed, involvement of the T3SS in elicitation of plant defense reactions has been recently suggested by $\mathrm{Oh}$ and associates (2010). In this article, the authors observed that $P$. fluorescens encoding a T3SS elicited more ROS production than $P$. fluorescens without a T3SS. Enhanced ROS production was found to be dependent on the presence of the HrpK1 translocator. Again, it was not possible to state that HrpK1 is the ROS elicitor due to the pleiotropic nature of the mutation. Similarly, Shin and Cornelis (2007) reported that pore formation by a multieffector mutant of Yersinia enterolitica triggers the maturation and release of proinflammatory IL-1 $\beta$. Therefore, triggering of the innate immune response might be a general feature of T3SS conserved between plant- and animal-pathogenic bacteria that are then suppressed by the injected effectors facilitating successful bacterial invasion.

\section{MATERIALS AND METHODS}

Bacterial strains, plasmids, and culture conditions.

The bacterial strains used in this study were the wild-type $E$. amylovora strain CFBP1430 (Paulin and Samson 1973) and its isogenic derivatives: the E. amylovora tts mutants PMV6023 (CFBP1430 hrcV::MuPR13) (Gaudriault et al. 1997) and PMV6119 (CFPB1430 hrcC::MuPR13) (Tharaud et al. 1994), the E. amylovora $d s p \mathrm{~A} / \mathrm{E}$ mutant M52 (CFBP1430 $d s p \mathrm{~A} / \mathrm{E}$ ::uidA-kan) (Gaudriault et al. 1997), the E. amylovora hrpN mutant PMV6112 (CFBP1430 hrpN::MuPR13) (Barny 1995), the E. amylovora hrpW mutant M56 (CFBP1430 hrpW::MudII1734) (Gauldriault et al. 1998), and the E. amylovora $h r p \mathrm{~N}-d s p \mathrm{~A} / \mathrm{E}$ mutant M64 (CFBP1430 hrpN::MuPR13, $d s p$ A/E::uidA-kan) (Venisse et al. 2003).

The two tts mutants, PMV6023 and PMV6119, have mutations in two different operons of the T3SS, the $h r p J$ operon and the $h r p C$ operon, respectively (Kim et al. 1997). For precise identification of the MuPR13 insertion site in the PMV6119 mutant, which was not mapped in a previous study (Tharaud et al. 1994), we amplified the border of the insertion using primers 4500F-U5662: ATTAGGCGGTGTAACCGGC and MuPR13: ATCTAATCCCATCAGATCC. The polymerase chain reaction (PCR) product was then sequenced with the MuPR13 primer, leading to identification of the MuPR13 insertion 1,482 nucleotides downstream from the $h r c \mathrm{C}$ start codon.

For construction of the E. amylovora hrpW-dspA/E mutant, pSL4, a pUC derivative containing a Strep-Omega cassette inserted in place of $d s p \mathrm{~A} / \mathrm{E}$, between the $d s p \mathrm{~A} / \mathrm{E}$ promoter and the $d s p \mathrm{~B} / \mathrm{F}$ gene, was introduced into the $h r p \mathrm{~W}::$ MudIIPR13 M69 mutant by electroporation. Marker exchange recombination was performed as previously described (Gaudriault et al. 1997) and we checked for recombination events by Southern blotting. A secretion test confirmed that E. amylovora hrpW$d s p \mathrm{~A} / \mathrm{E}$ was unable to secrete HrpW and DspA/E but retained the ability to secrete HrpN (data not shown). The resulting mutant (CFBP1430 $\Delta d s p \mathrm{~A}::$ Strep-Omega, hrpW::MuPR13) was named M82.

P. syringae DC3000 tts mutant was a gift from C. Manceau (Institut National de la Recherche Agronomique, Angers, France). 
Strains were grown routinely in Luria-Bertani (LB) broth or M9 minimal medium (Ausubel et al. 1995) at $30^{\circ} \mathrm{C}$. When necessary, the following antibiotics were added to the medium: ampicillin at $500 \mu \mathrm{g} / \mathrm{ml}$, chloramphenicol at $50 \mu \mathrm{g} / \mathrm{ml}$, kanamycin at $50 \mu \mathrm{g} / \mathrm{ml}$, and streptomycin at $100 \mu \mathrm{g} / \mathrm{ml}$.

Plasmid pMAB17 and pMAB65 are pRK767 (Gill and Warren 1988) and pUC18 derivatives, respectively, carrying the $h r p \mathrm{~N}$ gene cloned on a 1,3-kb HindIII fragment downstream of the pLac promoter.

\section{Plant materials.}

Apple seedlings were grown in the greenhouse for 3 weeks, until the six- to eight-leaf stage, before use. Seedlings were generated from seed obtained from open-pollinated 'Golden Delicious', which is susceptible to fire blight disease.

\section{Preparation of HrpN and HrpW.}

HrpN and HrpW were overproduced and purified from the Escherichia coli BL21 strain harboring pMAB164 or pMAB165, respectively, as previously described (Reboutier et al. 2007b).

\section{Adenylate cyclase assay.}

We investigated whether the HrpN effect was specific to the translocation of DspA/E or general to the translocation process by constructing a $\mathrm{C}$-terminal translational fusion in which CyaA was fused to the $200 \mathrm{~N}$-terminal amino acids of HrpN or HrpW. The HindIII-EcoRI fragment from pMS107 (Sory and Cornelis 1994) carrying the cyaA gene was first inserted into pUC18 to generate pSG28. Fragments carrying the $h r p \mathrm{~N}$ promoter and the first $600 \mathrm{bp}$ of the $h r p \mathrm{~N}$ gene or the $h r p \mathrm{~W}$ promoter and the first $600 \mathrm{bp}$ of the $h r p \mathrm{~W}$ gene were amplified by PCR, using pMAB 40 (Gaudriault et al. 1997) as template, with the following primers: $h r p \mathrm{~N}$, CGAGATCTTCCCGGCC TGCGTCCTTTCTT and CGAGATCTACGGCCGCCCAGCC CCAGTGC; and $h r p \mathrm{~W}$, CGAAGCTTAAAAGTCTGCCCCCC CTCACT and CGAAGCTTTTGAGCCATTTGCTCAATGGT. These fragments were inserted into pGEMT-easy (Promega, Madison, WI, U.S.A.) to give pSG43 and pSG41, respectively. The $h r p \mathrm{~N}$ and $h r p \mathrm{~W}$ fragments were then extracted from pSG43 and pSG41, respectively, by digestion with $B g l \mathrm{II}$ and HindIII, and inserted into pSG28 linearized by digestion with BglII or HindIII. The resulting plasmids, pSG46 and pSG44, respectively, carried the $h r p \mathrm{~N}$ or $h r p \mathrm{~W}$ promoter followed by in-frame fusions with the first $600 \mathrm{bp}$ of $h r p \mathrm{~N}$ or $h r p \mathrm{~W}$ and the cyaA gene.

We introduced pSG46 and pSG44 into the E. amylovora wild-type strain CFBP1430, the tts mutant PMV6023, and the $h r p \mathrm{~N}$ mutant PMV6112 by electroporation. These strains were grown on LB plates overnight, resuspended in water, and the density of the suspension was adjusted to an optical density at $600 \mathrm{~nm}\left(\mathrm{OD}_{600}\right)$ of 0.1 . Apple seedling leaves were vacuum infiltrated with these inocula. After $24 \mathrm{~h}$ at room temperature, three leaf disks $(0.8 \mathrm{~mm}$ in diameter) were collected and immediately frozen in liquid nitrogen.

For cAMP extraction, frozen leaf disks in Eppendorf tubes were ground by shaking with 2-mm tungsten beads in a Qiagen MM300 mixer mill, during two runs of 2 min each at $30 \mathrm{~Hz}$. We added $750 \mu \mathrm{l}$ of the Biotrak assay buffer and the resulting plant extracts were then incubated for $5 \mathrm{~min}$ in a boiling water bath. Insoluble debris was removed by centrifugation for $10 \mathrm{~min}$ at $4^{\circ} \mathrm{C}$ and $16,000 \times g$, and the protein content of the supernatant was determined by Bradford assay. We evaluated the cAMP levels in the supernatant with a cAMP enzyme immunoassay kit (Biotrak; Amersham Pharmacia Biotech, Piscataway, NJ, U.S.A.) according to the manufacturer's instructions.
Callose deposition, staining, and image analysis.

Three-week-old Golden Delicious apple seedlings were used. Before inoculation, seedlings were maintained in conditions of $100 \%$ humidity for $4 \mathrm{~h}$ to maximize stomatal opening. Apple leaf disks were infiltrated, under vacuum, with bacterial suspensions in water with an $\mathrm{OD}_{600}$ of 0.5 , with $10 \mu \mathrm{M}$ purified $\mathrm{HrpN}$ or $\mathrm{HrpW}$ proteins or with $1 \mu \mathrm{M}$ peptide flg22 (gift from L. Navarro). This method of inoculation is convenient to allow a large number of plant cells to be in the presence of the treatment at the same time. When whole plants are infected in this way, the E. amylovora wild-type strain produces systemic symptoms in the same manner as if it has been inoculated by conventional cutting of the youngest expanded leaf (Venisse et al. 2001, 2002, 2003). The inoculated leaf disks were incubated on wet filter paper at room temperature for $16 \mathrm{~h}$ before staining. Callose was stained with aniline blue, as previously described (Degrave et al. 2008), with the following modification: callose was stained for $1 \mathrm{~h}$ rather than $30 \mathrm{~min}$ in $0.01 \%$ aniline blue in $150 \mathrm{mM} \mathrm{K}_{2} \mathrm{HPO}_{4}(\mathrm{pH} 9.5)$ buffer.

Leaf disks were examined by epifluorescence microscopy, as previously described (Adam and Somerville 1996). For each leaf disk, at least 25 images were obtained, with an exposure time of $835 \mathrm{~ms}$. We did not take images of the edges, because wounding strongly induces callose deposition. Image J software was used for image analysis (Abramoff et al. 2004). The color image was transformed into 8-bit grayscale pictures, callose spots were counted, and the area (in pixels) of each callose spot was determined for each image. For each image, the sum of the areas of the callose spots was calculated to obtain a total area of callose deposition (Supplementary Fig. S1).

\section{Statistical analysis of callose images.}

Data were normalized by log transformation, and the variables considered for subsequent statistical analysis were the logarithms of the number of callose spots per image, or the logarithms of callose deposition area per image. Statistical analysis was carried out with $\mathrm{R}$ open-source software (R Development Core Team 2005). The means of these two variables were then compared between treatments in multiple paired Student's $t$ tests with Hochberg correction (Hochberg 1988).

\section{NBT staining.}

$\mathrm{O}_{2}^{-}$was detected in situ as described by Doke (1983) with some modifications. Leaves were vacuum-infiltrated with 0.05 M sodium phosphate buffer ( $\mathrm{pH} 7.5)$ containing $0.05 \%$ NBT. After $15 \mathrm{~min}$ of staining at room temperature under light, the NBT-treated tissues were placed in $96 \%$ (vol/vol) ethanol to stop the reaction, remove chlorophyll, and preserve tissue integrity.

\section{ACKNOWLEDGMENTS}

We thank D. Expert and F. van Gisjegem for critical reading of the manuscript, A. Edelman and associates for English corrections, J. Capelle for his help in performing the statistical analysis with the R software, $\mathrm{S}$. Genin for plasmid pMS107, L. Navarro for the flg22 peptide, C. Manceau for the $P$. syringae DC3000 tss mutant, and M.-N. Brisset for apple seedlings and help in the CyaA assay on apple plants.

\section{LITERATURE CITED}

Abramoff, M. D., Magelhaes, P. J., and Ram, S. J. 2004. Image processing with Image J. Biophotonics Int. 11:36-44.

Adam, L., and Somerville, S. C. 1996. Genetic characterization of five powdery mildew disease resistance loci in Arabidopsis thaliana. Plant J. 9:341-356.

Adam, A., Pike, S., Hoyos, M. E., Stone, J., Walker, J. C., and Novacky, A. 1997. Rapid and transient activation of a myelin basic protein kinase in tobacco leaves treated with harpin from Erwinia amylovora. Plant Physiol. 115:853-861. 
Ausubel, F. M., Brent, R., Kingston, R. E., Moore, D. D., Seidman, J. G., Smith, J. A., and Struhl, K. 1995. In: Current Protocols in Molecular Biology. John Wiley \& Sons, New York.

Baker, C. J., Orlandi, E. W., and Mock, N. M. 1993. Harpin, an elicitor of the HR in tobacco caused by Erwinia amylovora, elicits active oxygen production in suspension cells. Plant Physiol. 102:333-340.

Barny, M. A. 1995. Erwinia amylovora hrpN mutants blocked in harpin synthesis express a reduced virulence on host plant and elicit variable hypersensitive reactions on tobacco. Eur. J. Plant Pathol. 101:333-340.

Barny, M. A., Guinebretière, M. H., Marcais, B., Coissac, E., Paulin, J. P., and Laurent, J. 1990. Cloning of a large gene cluster involved in Erwinia amylovora CFBP1430 virulence. Mol. Microbiol. 4:777-786.

Block, A., Li, G., Fu, Z. Q., and Alfano, J. R. 2008. Phytopathogen type III effector weaponry and their plant targets. Curr. Opin. Plant Biol. 11:396-403.

Bocsanczy, A. M., Nissinen, R. I., Oh, C. S., and Beer, S. V. 2008. HrpN of Erwinia amylovora functions in the translocation of DspA/E into plant cells. Mol. Plant Pathol. 9:425-434.

Bogdanove, A. J., Kim, J. F., Wei, Z., Kolchinsky, P., Charkowski, A. O., Collmer, A., and Beer, S. V. 1998. Homology and functional similarity of an hrp-linked pathogenicity locus, $d s p \mathrm{EF}$, of Erwinia amylovora and the avirulence locus avrE of Pseudomonas syringae pv. tomato. Proc. Natl. Acad. Sci. U.S.A. 95:1325-1330.

Boller, T., and Felix, G. 2009. A renaissance of elicitors: Perception of microbe associated-molecular patterns and danger signals by pattern recognition receptors. Annu. Rev. Plant Biol. 60:379-406.

Boureau, T., El Maarouf-Bouteau, H., Garnier, A., Brisset, M. N., Perino, C., Pucheu, I., and Barny, M. A. 2006. DspA/E, a type III effector essential for Erwinia amylovora pathogenicity and growth in planta, induces cell death in host apple and non host tobacco plants. Mol. PlantMicrobe Interact. 19:16-24.

Bugert, P., and Geider, K. 1995. Molecular analysis of the ams operon required for exopolysaccharide synthesis of Erwinia amylovora. Mol. Microbiol. 15:917-933.

Cessna, S. G., and Low, P. S. 2001. Activation of the oxidative burst in aequorin transformed Nicotiana tabacum is mediated by protein kinase and anion channel dependent release of $\mathrm{Ca}^{2+}$ from internal stores. Planta 214:126-134.

Cessna, S. G., Messerli, M. A., Robinson, K. R., and Low, P. S. 2001 Measurement of stress induced $\mathrm{Ca}^{2+}$ pulses in single aequorin transformed tobacco cells. Cell Calcium 30:151-1156.

Cui, H., Xiang, T., and Zhou, J. M. 2009 Plant immunity: A lesson from pathogenic bacterial effector proteins. Cell. Microbiol. 11:1453-1461.

DebRoy, S., Thilmony, R., Kwack, Y. B., Nomura, K., and He, S. Y. 2004 A family of conserved bacterial effectors inhibits salicylic acid-mediated basal immunity and promotes disease necrosis in plants. Proc. Natl. Acad. Sci. U.S.A. 101:9927-9932.

De Capdeville, G., Beer, S. V., Watkins, C. B., Wilson, C. L., Tedeschi, L. O., and Aist, J. R. 2003. Pre- and Post- harvest harpin treatments of apple induces resistance to blue mold. Plant Dis. 87:39-44.

Degrave, A., Fagard, M., Perino, C., Brisset, M. N., Gaubert, S., Laroche, S., Patrit, O., and Barny, M.A. 2008. Erwinia amylovora type threesecreted proteins trigger cell death and defense responses in Arabidopsis thaliana. Mol. Plant-Microbe Interact. 21:1076-1086.

Doke N. 1983. Involvement of the superoxyde anion generation in the hypersensitive response of potato tuber tissues to infection with an incompatible race of and to the hyphal wall components. Physiol. Plant Pathol. 23:345-357.

Dong, H., Delaney, T. P., Bauer, D. W., and Beer, S. V. 1999. Harpin induces resistance in Arabidopsis through the systemic acquired resistance pathway mediated by salicylic acid and the Niml gene. Plant J. 20:207-215.

El-Maarouf, H., Barny, M. A., Rona, J. P., and Bouteau, F. 2001; Harpin, a hypersensitive response elicitor from Erwinia amylovora, regulates ion channels activities in Arabidopsis thaliana suspension cells. FEBS (Fed. Eur. Biochem. Soc.) Lett. 497:82-84.

Felix, G., Duran, J. D., Volko, S., and Boller, T. 1999. Plants have a sensitive perception system for the most conserved domains of bacterial flagellin. Plant J. 18:265-276.

Gaudriault, S., Malandrin, L., Paulin, J. P., and Barny, M. A. 1997. DspA, an essential pathogenicity factor of Erwinia amylovora showing homology with AvrE of Pseudomonas syringae, is secreted via the Hrp secretion pathway in a DspB-dependent way. Mol. Microbiol. 26:1057-1069.

Gaudriault, S., Brisset, M. N., and Barny, M. A. 1998. HrpW of Erwinia amylovora, a new Hrp-secreted protein. FEBS (Fed. Eur. Biochem. Soc.) Lett. 428:224-228.

Gill, P. R., and Warren, G. J. 1988. An iron-antagonized fungistatic that is not required for iron assimilation from a fluorescent rhizosphere Pseudomonad. J. Bacteriol. 170:163-170.

Guo, M., Tian, F., Wambolt, Y., and Alfano, J. R. 2009 The majority of type III effectory inventory of Pseudomonas syringae pv. tomato DC3000 can suppress plant immunity. Mol. Plant-Microbe Interact. 22:1069-1080.

Hauck, P., Thilmony, R., and He, S.Y. 2003. A Pseudomonas syringae type III effector suppresses cell wall-based extracellular defense in susceptible Arabidopsis plant. Proc. Natl. Acad. Sci. U.S.A. 100:8511-8582.

He, S. Y., Bauer, D. W., Collmer, A., and Beer, S.V. 1994. Hypersensitive response elicited by Erwinia amylovora harpin requires active plant metabolism. Mol. Plant-Microbe Interact. 7:289-292.

Heath, M.C. 2000 Hypersensitive response related death. Plant Mol. Biol. 44:321-334.

Hochberg, Y. 1988. A sharper Bonferroni procedure for multiple tests of significance. Biometrika 75:800-803.

Jones, J. D., and Dangl, J. L. 2006. The plant immune system. Nature 444:323-329.

Kim, J. F., and Beer, S. V. 1998. HrpW of Erwinia amylovora, a new harpin that contains a domain homologous to pectate lyases of a distinct class. J. Bacteriol. 180:5203-5210.

Kim, J. F., Wei, Z. M., and Beer, S. V. 1997. The hrpA and hrpC operons of Erwinia amylovora encode components of a type III pathway that secretes Harpin. J. Bacteriol. 179:1690-1697.

Kvitko, B. H., Ramos, A. R., Morello, J. E., Oh, H. S., and Collmer, A. 2007. Identification of harpins in Pseudomonas syringae pv. tomato DC3000, which are functionally similar to $\mathrm{HrpK} 1$ in promoting translocation of type III secretion system effectors. J. Bacteriol. 189:8059-8072.

Kvitko, B. H., Park, D. H., Velàsquez, A. C., Wei, C. F., Russel, A. B., Martin, G. B., Schneider, D. J., and Collmer, A. 2009. Deletions in the repertoire of Pseudomonas syringae pv. tomato DC3000 type III secretion effector genes reveal functional overlap among effectors. Plos Pathog. 5:e1000388.

Malnoy, M., Venisse, J. S., and Chevreau, E. 2005. Expression of a bacterial effector, HrpN, causes increased resistance to fire blight in Pyrus communis. Tree Genet. Genomes 1:41-49.

Nissinen, R. M., Ytteberg, A. J, Bogdanove, A. J., Van Wijk, K. J., and Beer, S. V. 2007. Analyses of the secretome of Erwinia amylovora and selected hrp mutants reveal novel type III secreted proteins and an effect of HrpJ on extracellular harpin levels. Mol. Plant Pathol. 8:55-57.

Oh, C. S., Martin, G. B., and Beer, S. V. 2007. DspA/E, a type III effector of Erwinia amylovora is required for early rapid growth in Nicotiana benthamiana and causes NbSGT1-dependent cell death. Mol. Plant Pathol. 8:255-265.

Oh, H. S., Park, D. H., and Collmer, A. 2010. Components of the Pseudomonas syringae type III secretion system can suppress and may elicit plant innate immunity. Mol. Plant-Microbe Interact. 23:727-739.

Paulin, J. P., and Samson, R. 1973. Le feu bactérien en France II. Caractères des souches d'Erwinia amylovora (Burril) Winslow et al. 1920 isolées du foyer franco-belge. Ann. Phytopathol. 5:389-397.

Peng, J. L., Dong, H. S., Dong, H. P., Delaney, T. P., Bonasera, J. M., and Beer, S. V. 2003. Harpin-elicited hypersensitive cell death and pathogen resistance require the NDR1 and EDS1 genes. Physiol. Mol. Plant Pathol. 62:317-326.

Percival, G. C., Noviss, K., and Haynes, I. 2009. Field evaluation of systemic inducing resistance chemicals at different growth stages for the control of apple (Venturia inaequalis) and pear (Venturia pirina) scab. Crop Prot. 28:629-633.

Pike, S. M., Adam, A. L., Pu, X. A., Hoyos, M. E., Laby, R., Beer, S. V., and Novacky, A. 1998. Effects of Erwinia amylovora harpin on tobacco leaf cell membranes are related to leaf necrosis and electrolyte leakage and distinct from perturbations caused by inoculated Erwinia amylo vora. Physiol. Mol. Plant Pathol. 53:39-60.

Popham, P. L., Pike, S. M., and Novacky, A. 1995. The effects of harpin from Erwinia amylovora on the plasmalemma of suspension-cultured tobacco cells. Physiol. Mol. Plant Pathol. 47:39-50.

R Development Core Team 2005. R: A language and environment for statistical computing. R Foundation for Statistical Computing, Vienna.

Reboutier, D., Frankart, C., Briand, J., Biligui, B., Laroche, S., Rona, J. P., Barny, M. A., and Bouteau, F. 2007a. The HrpNea Harpin from Erwinia amylovora triggers differential responses on the nonhost Arabidopsis thaliana cells and on the host apple cells. Mol. Plant-Microbe Interact. 20:94-100.

Reboutier, D., Frankart, C., Briand, J., Biligui, B., Rona, J. P., Haapalainen, M., Barny, M. A., and Bouteau, F. 2007b. Antagonistic action of harpin proteins: HrpWea from Erwinia amylovora suppresses HrpNea induced cell death in Arabidopsis thaliana. J. Cell Sci. 120:3271-3278.

Shin, H., and Cornelis, G. R. 2007. Type III secretion translocation pores of Yersinia enterolitica trigger maturation and release of pro-inflammatory IL-1b. Cell. Microbiol.12:2893-2902.

Sory, M. P., and Cornelis, G. R. 1994. Translocation of a hybrid YopE adenylate cyclase from Yersinia enterocolitica into Hela-Cells. Mol. Microbiol. 14:583-594. 
Tharaud, M., Menggad, M., Paulin, J. P., and Laurent, J. 1994. Virulence, growth, and surface characteristics of Erwinia amylovora mutants with altered pathogenicity. Microbiology 140:659-669.

Tsuda, K., Sato, M., Glazebrook, J., Cohen, J. D., and Katagari, F. 2008. Interplay between MAMP-triggered and SA-mediated defense responses. Plant J. 53:763-775.

Venisse, J. S., Gullner, G., and Brisset, M. N. 2001. Evidence for the in volvement of an oxidative stress in the initiation of infection of pear by Erwinia amylovora. Plant Physiol. 125:2164-2172.

Venisse, J. S., Malnoy, M., Faize, M., Paulin, J. P., and Brisset, M. N. 2002. Modulation of defense responses of Malus spp. during compatible and incompatible interactions with Erwinia amylovora. Mol. PlantMicrobe Interact. 15:1204-1212.

Venisse, J. S., Barny, M. A., Paulin, J. P., and Brisset, M. N. 2003. Involve- ment of three pathogenicity factors of Erwinia amylovora in the oxidative stress associated with compatible interaction in pear. FEBS (Fed. Eur. Biochem. Soc.) Lett. 537:198-202.

Wei, Z. M., Laby, R. J., Zumoff, C. H., Bauer, D. W., He, S. Y., Collmer, A., Beer, S. V. 1992. Harpin, elicitor of the hypersensitive response produced by the plant pathogen Erwinia amylovora. Science 257:85-88.

Zipfel, C., Robatzek, S., Navarro, L., Oakeley, E. J., Jones, J. D., Felix, G., and Boller, T. 2004. Bacterial disease resistance in Arabidopsis through flagellin perception. Nature 428:764-767.

\section{AUTHOR-RECOMMENDED INTERNET RESOURCE}

The R Project for Statistical Computing website: www.R-project.org 